\title{
Sistem Informasi Mahasiswa Asing
}

\author{
Hari Robiansyah, Linda Salma Angreani
}

\begin{abstract}
A residence permit is permission given to foreigners by Immigration Officials or foreign-service officer to be in the region of Indonesia in a certain period of time. Foreign students studying in Indonesia must have a residence permit in order to continue learning in Indonesia. Residence permit have a time limit and must always be extended before it expires (overstayed). Foreign student information system and a reminder of this residence permit are systems built to help foreign students of UIN Maulana Malik Ibrahim Malang in reminding the residence permit problems. This research uses Agile Development with Scrum model in development. GNU All Mobile Management Utilities (GAMMU) is used for sending SMS (Short Message Service), and Cron program is used for running SMS commands automatically each day. The results of this research are the foreign student information system and reminder that automatically provide reminder in the form of SMS to foreign students whose the validity period of residence permit will run out.
\end{abstract}

Index Terms-Residence Permits, Overstay, Reminder, Agile, Scrum, Gammu, Cron.

Abstrak--Izin tinggal adalah izin yang diberikan kepada orang asing oleh Pejabat Imigrasi atau pejabat dinas luar negeri untuk berada di wilayah Indonesia dalam kurun waktu tertentu. Mahasiswa asing yang belajar di Indonesia harus memiliki izin tinggal untuk bisa terus belajar di Indonesia. Izin tinggal memiliki batas waktu (limit) dan harus selalu diperpanjang sebelum habis masa berlakunya (overstay). Sistem informasi mahasiswa asing ini merupakan sebuah sistem yang dibangun untuk membantu mahasiswa asing dilingkungan Universitas Islam Negeri Maulana Malik Ibrahim dalam mengingatkan masalah izin tinggal tersebut. Penelitian ini menggunakan Agile Development Software dengan model Scrum dalam pengembangannya. GNU All Mobile Management Utilities(GAMMU) digunakan untuk mengirimkan SMS (Short Message Service), dan untuk menjalankan perintah SMS secara otomatis setiap hari digunakan program Cron. Hasil dari penelitian ini adalah sistem informasi mahasiswa asing yang secara otomatis

Manuscript received January 22, 2017. This work was supported in part by Informatics Engineering Department of Maulana Malik Ibrahim Islamic State University.

Hari Robiansyah is with the Informatic Engineering Departemen of Maulana Malik Ibrahim Islamic State University, Malang, Indonesia (corresponding author provide phone 085758206435 ; email robiansyah26@gmail.com).

Linda Salma Angreani is with the Informatic Engineering Departement of Maulana Malik Ibrahim Islamic State University, Malang, Indonesia (corresponding author provide phone 08585598 9930; email lindasalma@ gmail.com) memberikan pengingat (reminder) berupa SMS kepada mahasiswa asing yang akan habis masa belaku izin tinggalnya.

Kata Kunci-Izin Tinggal, Overstay, Reminder, Agile, Scrum, GAMMU, Cron.

\section{PENDAHULUAN}

$\mathrm{U}$ niversitas Islam Negeri (UIN) Maulana Malik Ibrahim (Maliki) Malang merupakan salah satu Perguruan Tinggi Agama Islam (PTAI) terbesar di Indonesia dengan banyak prestasi. Mahasiswa asing yang datang ke UIN Maulana Malik Ibrahim tidak hanya untuk melanjutkan studi (S1, S2, dan S3), tetapi ada juga yang datang untuk kursus singkat (short course) tentang Bahasa Indonesia dan kebudayaan Islam. Kini mahasiswa asing di UIN Maulana Malik Ibrahim berjumlah kurang lebih 250 orang dari 29 negara antara lain Malaysia, Singapura, Thailand, Papua New Ginie, Madagaskar, Sudan, Libia, Filipina, Rusia dan bebarapa negara lain. Jumlah ini merupakan jumlah mahasisa asing terbanyak dari setiap PTAI yang ada dan menjadi prestasi yang luar biasa bagi UIN Maulana Malik Ibrahim.

Tentunya jumlah mahasiswa asing yang datang ke UIN Maulana Malik Ibrahim diharapkan akan bertambah setiap tahunnya, sehingga dibutuhkan pemantauan yang lebih ekstra terhadap mahasiswa asing tersebut baik dalam segi keilmuan, tempat tinggal maupun terkait tentang perizinan mereka di Indonesia dan lain-lain. Masalah yang sering dihadapi oleh mahasiswa asing yang ada di UIN Maulana Malik Ibrahim maupun di seluruh Indonesia adalah masalah izin tinggal melebihi batas waktu yang telah ditentukan (overstay).

Overstay merupakan pelanggaran ataupun pidana keimigrasian yang diatur pada Pasal 78 Undang-Undang Nomor 6 Tahun 2011 tentang Keimigrasian. Di dalam pasal tersebut dijelaskan bahwa Warga Negara Asing (WNA) pemegang Izin Tinggal yang telah berakhir masa berlakunya dan masih berada dalam wilayah Indonesia kurang dari 60 hari dikenai biaya beban sesuai dengan ketentuan perundang-undangan, Apabila melebihi 60 hari dari batas waktu izin tinggal dikenai Tindakan Administratif Keimigrasian berupa Deportasi dan Penangkalan [1].

Banyak kerugian yang telah ditimbulkan oleh overstay, baik secara materil maupun non materil. 
Secara materil mahasiswa asing yang overstay harus membayar denda sesuai dengan ketentuan perundangundangan terhitung semenjak berakhirnya masa berlaku izin tinggal mereka sampai dilakukan perpanjangan izin tinggal kembali. Sedangkan kerugian non materil, mahasiswa asing tersebut bisa di deportasi dari Indonesia dan dipidanakan serta pihak sponsor juga akan dikenakan hukuman sesuai perundang-undangan yang berlaku.

Oleh karena itu, diperlukan sebuah sistem yang bisa memberikan pengingat(reminder) terhadap masa berakhir izin tinggal khususnya dan pemantauan terhadap mahasiswa asing baik dalam segi keilmuan, prestasi, tempat tinggal dan lain-lain umumnya, dalam hal ini akan dibangun "Sistem Informasi Mahasiswa Asing".

\section{DASAR TEORI}

\section{A. Cron}

Cron merupakan program daemon yang setiap menit men-cek apakah ada perintah yang mesti dijalankan. Daftar atau tabel cron (crontab), yaitu file yang berisi jadwal perintah, ada di direktori spool (misalnya /var/spool/cron/). Nama file itu sama dengan nama user pemilik atau pembuat jadwal. Untuk membuat atau mengedit crontab, user dapat menggunakan program yang juga bernama crontab. Sebagai root, kita dapat mengedit langsung file crontab yang ada di direktori spool cron tersebut [2].

\section{B. Agile}

Kata Agile berarti bersifat cepat, ringan, bebas bergerak, waspada. Kata ini digunakan sebagai kata yang mengambarkan konsep model proses yang berbeda dari konsep model-model proses yang sudah ada. Konsep Agile Software Development dicetuskan oleh Kent Beck dan 16 rekannya dengan menyatakan bahwa Agile Software Development adalah cara membangun software dengan melakukannya dan membantu orang lain membangunnya sekaligus.

Dalam Agile Software Development interaksi dan personel lebih penting dari pada proses dan alat, software yang berfungsi lebih penting daripada dokumentasi yang lengkap, kolaborasi dengan klien lebih penting dari pada negosiasi kontrak, dan sikap tanggap terhadap perubahan lebih penting daripada mengikuti rencana [3].

\section{Scrum}

Scrum(kb): sebuah kerangka kerja di mana orangorang dapat menyelesaikan permasalahan kompleks yang senantiasa berubah, di mana pada saat bersamaan menghasilkan produk dengan nilai setinggi mungkin secara kreatif dan produktif [4].

Scrum adalah proses kerangka kerja yang telah digunakan semenjak tahun 1990 untuk mengelola pengembangan produk yang kompleks. Scrum bukanlah sebuah proses atau teknik untuk membuat produk, melainkan sebuah kerangka kerja dimana didalamnya kita dapat memasukkan berbagai proses dan teknik.
Scrum akan menunjukkan hasil dari praktik pengelolaan dan pengembangan produk sehingga kita dapat terus menjadi lebih baik [4].

\section{Product Backlog}

Product backlog adalah daftar terurut, dari setiap hal yang berkemungkinan dibutuhkan didalam produk, dan juga merupakan sumber utama, dari daftar kebutuhan mengenai semua hal yang perlu dilakukan terhadap produk. Product owner bertanggung jawab terhadap product backlog, termasuk isinya, ketersediaannya, dan urutannya [4].

\section{E. Sprint}

Sprint merupakan sebuah batasan waktu selama satu bulan atau kurang, dimana potongan-potongan produk yang telah selesai disusun, berpotensi untuk dikembangkan. Sprint dapat dikatakan sebagai sebuah proyek dengan batasan waktu tidak lebih dari satu bulan. Sama halnya dengan proyek, Sprint digunakan untuk menyelesaikan sesuatu. Setiap Sprint memiliki definisi mengenai apa yang akan dikembangkan, sebuah desain dan perencanaan yang fleksibel.

Sprint biasanya memiliki durasi yang konsisten sepanjang proses pengembangan produk. Sprint yang baru, langsung dimulai setelah sprint yang sebelumnya berakhir. Sprint terdiri dari Sprint Planning, Daily Scrum, Sprint Review dan Sprint Retrospective [4].

\section{F. SMS Gateway}

SMS Gateway merupakan perangkat penghubung antara pengirim SMS dengan basis data. Perangkat ini terdiri satu set PC, telepon dan program aplikasi. Program aplikasi ini yang akan meneruskan setiap permintaan/request dari setiap SMS yang masuk dengan melakukan query ke dalam basis data, kemudian diberi respon dari hasil query kepada si pengirim. Artinya, SMS tersebut harus bisa melakukan transaksi dengan basis data. Untuk itu perlu dibangun sebuah sistem yang disebut sebagai SMS Gateway [5].

Pada prinsipnya, SMS Gateway adalah sebuah perangkat lunak yang menggunakan bantuan komputer dan memanfaatkan teknologi seluler yang diintegrasikan untuk mendistribusikan pesan-pesan yang di generate lewat sistem informasi melalui media SMS yang ditangani oleh jaringan seluler [6].

\section{ANALISI DAN PERANCANGAN SISTEM}

\section{A. Analisis Kebutuhan Sistem}

Sistem Informasi Mahasiswa Asing merupakan sebuah sistem informasi yang membantu pihak kemahasiswaan bagian mahasiswa asing dalam melakukan tugas/kerja mereka. Adapun area tugas/kerja mereka antara lain sebagai berikut :

1. Perpanjangan ITK (Izin Tinggal Kunjungan) ke I-IV

2. Alih Status Izin Kunjungan (ITK) menjadi Izin Tinggal Terbatas (ITAS)

3. Alih Status dari Visa Izin Tinggal Terbatas (VITAS)

menjadi Izin Tinggal Terbatas (ITAS)

4. Penangguhan Izin Tinggal (ITK dan ITAS) 
5. Perpanjangan Izin Tinggal Terbatas (ITAS)

6. Exit-Reentry Permit (Single/Multiple ERP)

7. Exit Permit Only (EPO)

8. Pengalihan Sponsor

9. Pindah Domisili

10.Pengajuan Rekomendasi Izin Tinggal

11.Pengajuan Rekomendasi Perpanjangan Izin Tinggal Terbatas (ITAS)

12.Pencabutan Sponsor

13. Surat Keterangan Lapor Diri (SKLD) dari kepolisian Daerah

14. Surat sponsorship bagi mahasiswa yang keluar dari wilayah RI sebelum mendapat ITAS dan calon mahasiswa baru untuk mendapatkan Izin Tinggal di KBRI

15.Perpanjangan paspor mahasiswa asing di Kedutaan atau Kantor Perwakilan Negara masing-masing

16.Pengurusan overstay

Adapun alur alih status Izin Tinggal Kunjungan (ITK) menjadi Izin Tinggal Terbatas (ITAS) sebagai berikut :

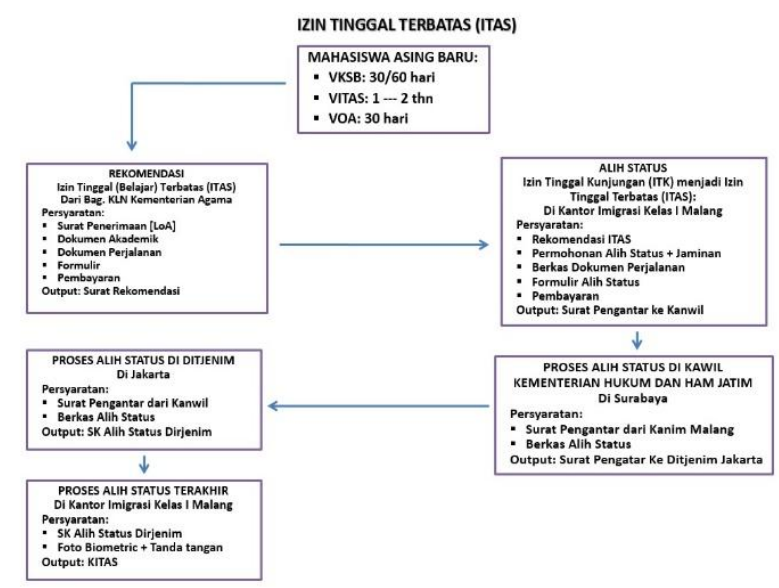

Gambar1. Alur Alih Status Izin Tinggal Kunjungan (ITK) Menjadi Izin Tinggal Terbatas (ITAS)

\section{B. Perencanaan Sistem}

\section{Product Bakclog}

Pada tahap ini akan dijelaskan rancangan product backlog dari sistem informasi mahasiswa asing yang diambil dari analisis kebutuhan sistem yang telah dijelaskan sebelumnya. Perancangan product backlog ini dilakukan menggunakan software taiga.io yang bisa diakses pada alamat https://tree.taiga.io. Adapunperancanganproduct backlog dapat dilihat pada Gambar 2

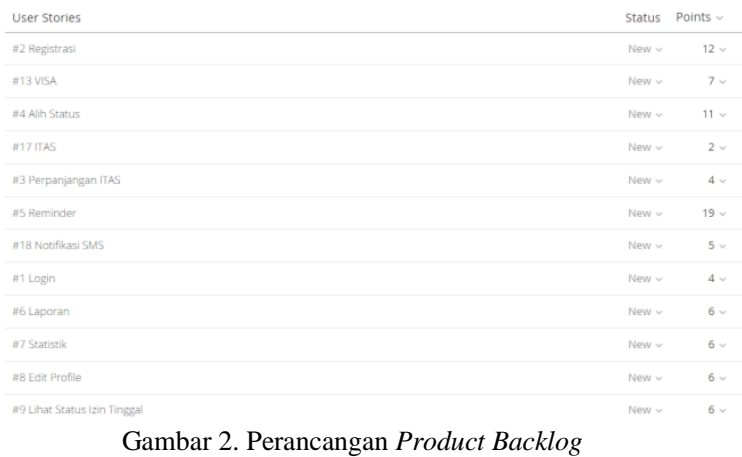

Gambar 2. Perancangan Product Backlog

\section{Usecase Diagram}

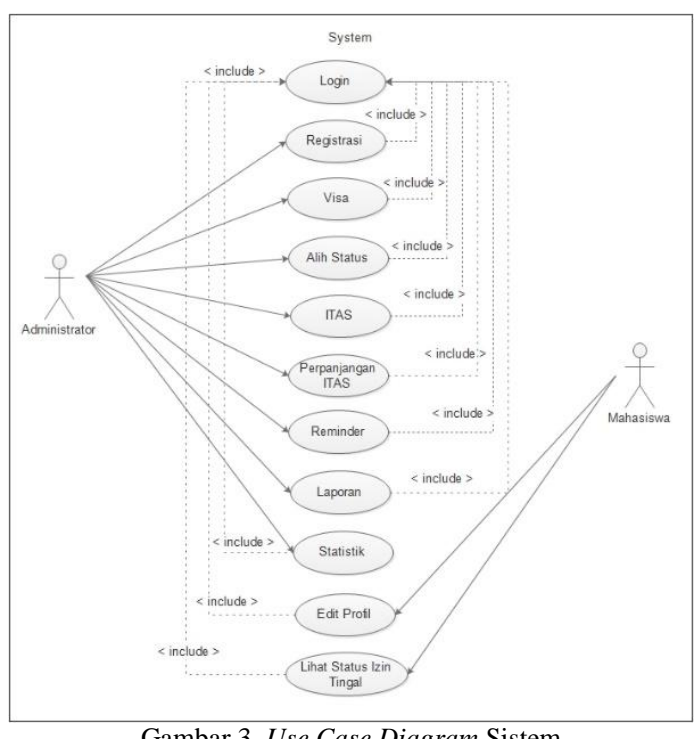

Deskripsi penjelasan aktor pada sistem ini dapat dilihat pada Tabel 1

\begin{tabular}{lcl}
\multicolumn{2}{l}{ Table 1.Definisi Aktor dalam Use Case } \\
\hline \hline No & Aktor & \multicolumn{1}{c}{ Deskripsi } \\
\hline 1 & Mahasiswa & $\begin{array}{l}\text { Orang yang dapat mendapatkan } \\
\text { pengingat/reminder mengenai batas waktu } \\
\text { izin tinggal, edit profil dan melihat status } \\
\text { visa. }\end{array}$ \\
& Administrator & $\begin{array}{l}\text { Orang yang mengontrol sistemyaitu } \\
\text { mengontrol registrasi, peralihan dan } \\
\text { perpanjangan visa dan lain-lain. }\end{array}$ \\
\hline
\end{tabular}

Selanjutnya, pendefinisian use case dijelaskan secara detail pada Tabel 2

Table 2.Definisi Use Case

\begin{tabular}{|c|c|c|}
\hline No & $\begin{array}{l}\text { Nama Use } \\
\text { Case }\end{array}$ & Deskripsi \\
\hline 1 & Registrasi & Menampilkan halaman dan form registrasi \\
\hline 2 & Visa & $\begin{array}{l}\text { Menampilkan data visa mahasiswa sesuai } \\
\text { jenisnya beserta aksi perpanjang dan } \\
\text { proses alih status }\end{array}$ \\
\hline 3 & Alih status & $\begin{array}{l}\text { Menampilkan halaman dan formuntuk } \\
\text { melakukan proses alih status izin tinggal }\end{array}$ \\
\hline 4 & ITAS & $\begin{array}{l}\text { Menampilkan data ITAS mahasiswa } \\
\text { beserta proses perpanjangan }\end{array}$ \\
\hline 5 & $\begin{array}{l}\text { Perpanjangan } \\
\text { ITAS }\end{array}$ & $\begin{array}{l}\text { Menampilkan halaman dan form untuk } \\
\text { melakukan proses perpanjangan izin } \\
\text { tinggal terbatas (ITAS) }\end{array}$ \\
\hline 6 & Reminder & $\begin{array}{l}\text { Menampilkan halaman untuk mengelola } \\
\text { izin tinggal dan paspor mahasiswa asing } \\
\text { yang akan habis masa berlakunya }\end{array}$ \\
\hline 7 & Laporan & $\begin{array}{l}\text { Menampilkan halaman untuk mencetak } \\
\text { laporan mahasiswa dan izin tinggal }\end{array}$ \\
\hline 8 & Statistik & $\begin{array}{l}\text { Menampilkan halaman grafik statistika } \\
\text { mahasiswa asing berdasarkan kategori }\end{array}$ \\
\hline 9 & Profil & $\begin{array}{l}\text { Menampilkan halaman dan form untuk } \\
\text { mengedit data pribadi mahasiswa }\end{array}$ \\
\hline 10 & $\begin{array}{l}\text { Status izin } \\
\text { tinggal }\end{array}$ & $\begin{array}{l}\text { Menampilkan halaman berupa status izin } \\
\text { tinggal mahasiswa beserta keluarga }\end{array}$ \\
\hline
\end{tabular}

\section{HASILDANPEMBAHASAN}

\section{A. Pengujian Sistem}

Pengujian sistem informasi mahasiswa asing dan reminder ini dibagi menjadi dua tahapan yaitu tahap pengujian Alpha mneggunakan metode black box dan 
tahap pengujian Beta menggunakan model angket/kuesioner.

\section{B. Pengujian Alpha}

Pengujian yang dilakukan dengan menguji sistem secara keseluruhan dengan metode pengujian alpha. Adapun pengujian alpha yang akan dilakukan dapat dilihat pada Tabel 3.

Table 3. Pengujian Alpha Sistem Informasi Mahasiswa Asing

\begin{tabular}{lll}
\hline \hline \multicolumn{1}{c}{$\begin{array}{c}\text { Menu yang } \\
\text { diuji }\end{array}$} & \multicolumn{1}{c}{ Detail Pengujian } & \multicolumn{1}{c}{$\begin{array}{c}\text { Jenis } \\
\text { Pengujian }\end{array}$} \\
\hline Login & Login Sebagai Administrator & Black box \\
& Login sebagai mahasiswa & Black box \\
Pengolahan & Menambah data mahasiswa & Black box \\
data mahasiswa & Mengubah data mahasiswa & Black box \\
$\begin{array}{l}\text { Pengolahan } \\
\text { data visa }\end{array}$ & Memperpanjang data visa & Black box \\
$\begin{array}{l}\text { Pengolahan } \\
\text { data ITAS }\end{array}$ & Mengalih statuskan data visa & Balck box \\
\hline \hline
\end{tabular}

\section{Pengujian Beta}

Pada pengujian beta akan dilakukan pengujian dengan cara menyebar angket atau kuesioner kepada 10 orang responden mengenai kepuasan user yaitu :

Table 4. Daftar Responden

\begin{tabular}{llc}
\multicolumn{1}{c}{ Responden } & Jenis User & $\begin{array}{c}\text { Jumlah } \\
\text { (Orang) }\end{array}$ \\
\hline \hline $\begin{array}{l}\text { Staff kemahasiswaan UIN Malang } \\
\text { urusan mahasiswa asing } \\
\text { Mahasiswa }\end{array}$ & Administrator & 3 \\
\hline \hline
\end{tabular}

\section{Pengujian Notifikasi SMS}

Pengujian notifikasi SMS ini dilakukan dengan cara menginputkan 10 no handphone $(\mathrm{Hp})$ mahasiswa ke dalam sistem dan sisa waktu izin tinggal mereka di atur dalam batas waktu pemberian reminder (pengingat) yaitu H-10 untuk jenis Visa Kunjungan Sosial Budaya (VKSB), H-30 untuk Visa Izin Tinggal Terbatas (VITAS) dan Izin Tinggal Terbatas (ITAS) serta H-180 untuk paspor.

Hasil pengujian notifikasi SMS kepada 10 mahasiswa secara bersamaan dapat dilihat pada Tabel 5.

Table 5. Hasil Pengujian Notifikasi SMS

\begin{tabular}{cccccc}
\hline \hline No & No Hp & $\begin{array}{c}\text { Jenis } \\
\text { Reminder }\end{array}$ & Terkirim & $\begin{array}{c}\text { Ga } \\
\text { gal }\end{array}$ & $\begin{array}{c}\text { Kesesu } \\
\text { aian } \\
\text { Pesan }\end{array}$ \\
\hline 1 & 085755755125 & VKSB & $\sqrt{ }$ & & Ya \\
2 & 085648950408 & VKSB & $\sqrt{ }$ & - & Ya \\
3 & 085764038702 & VKSB & - & $\sqrt{ }$ & - \\
4 & 082331267081 & VITAS & $\sqrt{ }$ & - & Ya \\
5 & 082338248836 & VITAS & $\sqrt{ }$ & - & Ya \\
6 & 085749354390 & ITAS & $\sqrt{ }$ & - & Ya \\
7 & 082231012357 & ITAS & $\sqrt{ }$ & - & Ya \\
8 & 085646497446 & PASPOR & $\sqrt{ }$ & - & Ya \\
9 & 085745777960 & PASPOR & $\sqrt{ }$ & - & Ya \\
10 & 085799131849 & PASPOR & $\sqrt{ }$ & - & Ya \\
\hline \hline
\end{tabular}

Dari 10 nomor handphone yang dimasukkan, 9 nomor berhasil mendapatkanSMS notifikasi sesuai dengan jenis reminder / pengingatnya, hanya 1 nomor yang tidak mendapatkan SMS notifikasi karena kesalahan nomor handphone yang diinputkan.

\section{KESIMPULAN}

Dari hasil penelitian yang telah dilakukan selama proses analisis, perancangan dan pengujian sistem informasi mahasiswa asing pada bagian kemahasiswaan Universitas Islam Negeri Maulana Malik Ibrahim Malang menggunakan metode srcum dapat diambil kesimpulan bahwa :

1.Penelitian ini berhasil membuat sistem informasi menggunakan metode scrum yang bisa diakses oleh staff kemahasiswaan dan mahasiswa asing UIN Maulana malik Ibrahim Malang;

2. Penelitian ini berhasil mengimplementasikan crontab untuk menjalankan source code secara otomatis untuk mengirimkan SMS dan email kepada mahasiswa asing UIN Maulana Malik Ibrahim Malang;

3. Penelitian ini berhasil mengimplementasikan SMS Gateway kedalam sistem informasi mahasiswa asing.

Ada beberapa saran yang peneliti sarankan agar sistem ini lebih baik dan lebih lengkap, diantaranya :

1. Sistem bisa dikembangkan lagi dengan menambahkan fitur yang tidak mengingatkan tentang izin tinggal tetapi juga masalah akademik mahasiswa asing;

2. Dibuat berbasis android agar mempermudah user;

3. Integrasi dengan sistem yang sudah ada seperti SIAKAD (Sistem Informasi Akademik) atau SISFO (Sistem Informasi) Kampus.

\section{REFERENCES}

[1] R. I. Peraturan Pemerintah Republik Indonesia Nomor 31 Tahun 2013 Tentang Peraturan Pelaksanaan Undang-Undang Nomor 6 Tahun 2011 Tentang Keimigrasian, Jakarta: Sekretariat Negara, 2013.

[2] E. Purwanto, Network Monitoring System (NMS) dengan Notifikasi Menggunakan SMS Studi Kasus pada Divisi NOC PT. Melvar Lintasnusa, Skripsi. Bandung: Jurusan Teknik Informatika, Fakultas Teknik dan Ilmu Komputer, UNIKOM, 2007.

[3] S. W. Ambler, An Introducation to Agile Modeling, Agile Modeling Home Page, 2008.

[4] K. Schwaber and S. Jeff, "Panduan Scrum," 2013. [Online]. Available: http://www.scrum.org/storage/scrum guides/Scrum\%20Guide\%20-\%20ID.pdf.

[5] Zahra, Sistem Pendaftaran Pelatihan di Lembaga Pengembangan Pendidikan, Program Diploma III Ilmu Komputer. Surakarta: Fakultas Matematika dan Ilmu Pengetahuan Alam, Universitas Sebelas Maret, 2011.

[6] J. Triyono, "Pelayanan KRS On-line berbasis SMS," Jurnal Teknologi, Vol. 3 No. 1, pp. 33-38, 2010. 